\title{
Genistein Increase Intracellular Distribution of the High Motility Group Box-1 through p38 Pathway in HeLa culture cells induced by Tumor Necrosis Factor- $\alpha$
}

\author{
Merlita Herbani ${ }^{1 *}$, Aris Widodo ${ }^{1}$, Hidayat Sujuti ${ }^{2}$ \\ ${ }^{1}$ Pharmacology Department, Brawijaya Faculty of Medicine, Malang, Indonesia, 65145 \\ ${ }^{2}$ Biochemistry and Biomolecular Department, Brawijaya Faculty of Medicine, Malang, Indonesia, 65145
}

\begin{abstract}
Cervical cancer is one kind of many cancers that cause death to women around the world. Many studies had support the statement that inflammation has a strong linkage with cancer development. Several factors like proinflammatory factor can influence tumor cell microenvironment, and induce a faster proliferation. TNF- $\alpha$ is suspected can induce proliferation. While cancer itself can induce inflammation, which is marked by several marker. One of them is HMGB1, released from the cell as active secretory lysosomes or passive diffusion. Genistein has demonstrated growth inhibitory effects of various types of cancer cells. It inhibits tyrosine kinase pathway, which can be activated by TNF- $\alpha$. One of those pathways that have the link with proliferation is $\mathrm{p} 38$. This study tries to reveal about inhibitory effect of genistein toward p38 pathway that had been activated by TNF- $\alpha$. This research was conducted by exposing cultured HeLa cells with various doses of genistein for 90 minutes, and then exposed to TNF- $\alpha 10 \mathrm{ng} / \mathrm{mL}$ for 20 minutes. Observations were made with a confocal microscope, by staining the cells with pp38-TRITC and HMGB1 antibody. The intensity was measured and analyzed by Fluoview software. The results suggest that there be significant differences between pp38 intranuclear intensity and HMGB1 extranuclear intensity of each dose of genistein ( $p=0.000$, ANOVA). pp38 and HMGB1 intensity were increased along with increasing genistein dose, but at high dose there were noted decreasing of pp38 and HMGB1 intensity. At apoptotic dose, pp38 and HMGB1 intensity were increased markedly, showing the effect of apoptosis. In general, increasing doses of genistein increase intranuclear p38 activation and HMGB1 extranuclear translocation. So there were a strong linkage between p38 activation and HMGB1 translocation in this study.
\end{abstract}

Keywords: Genistein, TNF-a, Hela Cells, HMGB1, $p 38$

\section{INTRODUCTION}

Cervical cancer is one kind of many cancers that cause death to women around the world [1]. Until now, cervical cancer is treated by operative, chemotherapy and radiotherapy, depend on its stadium [2]. Several studies had support the statement that inflammation has a strong linkage with cancer development. Many pathways are involved, example like cyclooxygenase (COX-1 and

\footnotetext{
${ }^{*}$ Corresponding author:

Merlita Herbani

Trunojoyo I/14 Batu, 65312

E-mail: merlita.herbani@gmail.com
}

-2), free radicals, TGF- $\beta$ and TNF- $\alpha$ [3]. Several factors like proinflammatory factor can influence tumor cells microenvironment, and induce a faster proliferation $[4,5]$. TNF- $\alpha$ is suspected can induce proliferation through $\mathrm{NF- \textrm {KB }}$ pathway [3]. In his review, Rakoff-Nahoum also writes cancer also induce inflammation, which marked by HMGB1 release. HMGB1 is an intranuclear protein, together histone they folded DNA and a parted when the DNA transcription process happen. It is a mobile molecule and can migrate from the nucleus to the cytoplasm through the nuclear pore [6]. It serves as a cytokine when released in the extracellular environment by inflamed and necrotic cells [7]. After translated, HMGB1 undergone various modifications to be 
able to function. One important modification that occurs on HMGB1 is acetylation, which causes HMGB1 out of the cell nucleus and can not return to the nucleus [8]. Acetylated HMGB1 will come out actively as secretory lysosomes [9]. Outside the cell, it bounded firmly to the RAGE receptor which is a potent mediator for inflammation [10]. HMGB1 overexpression inhibits apoptosis, which supports the argument that these molecules may act as antiapoptotic oncoprotein, and HMGB1 expression found increase in several different tumor types [11]. Thus, allegedly HMGB1 translocation from nucleus into the cytoplasm of the cancer cells can affect defense toward apoptosis. A model of the nature of cancer cells is HeLa cells culture. HeLa cell is a cell culture derived from a tissue biopsy of the cervix uteri Henrietta Lacks, a cervical cancer patients which taken in 1951 [12]. HeLa cells that induced by TNF- $\alpha$ can provide an illustration of the role of chronic inflammation in cancer. In a previous study, it was found that the induction of TNF- $\alpha$ in HeLa cell cultures can increase HMGB1 translocation from the nucleus to the cytoplasm, which may imply that the inflammatory pathway in this cell culture has been activated. From this preliminary research, allegedly that the pathways involved in the induction of HMGB1 translocation from the nucleus to the cytoplasm is the MAPK pathway. One group of protein kinases that are activated by inflammatory cytokines is p38. TNF and IL- 1 activates p38 iso-forms to encourage the deployment of TRAF adapter proteins to the intracellular domain of the receptor origin. TRAF deployment activate various of MAPKKK involved in the activation of p38 [13]. Thus, it can be presumed that the induction of TNF $-\alpha$ activates the p38 pathway that encourages the release of HMGB1. The release of the intranuclear molecules will exacerbate the inflammatory process and promote the occurrence of metastasis. Genistein which is the major isoflavones found in soybeans, has demonstrated growth inhibitory effects of various types of cancer cells in vitro and vivo without toxicity to normal tissues [14]. It inhibits protein-tyrosine kinase and topoisomeraseII activity (DNA topoisomerase, type II), and is used as an antineoplastic and antitumor agent. Genistein can modify histone $\mathrm{H} 3$ with acetylate the histone proteins [15]. This study is trying to uncover the potential of genistein as the new hope of the cancer management, especially cervical cancer. In this study, genistein can inhibit the translocation of HMGB1 allegedly from the nucleus to the cytoplasm, which is activated by the p38 pathway in cultured HeLa cells induced by TNF $-\alpha$. Thus, further research on the potential of genistein can be done.

\section{MATERIALS AND METHODS}

\section{Cell Lines}

Hela cells were obtained from ATCC. HeLa cells were cultured in Modified Eagle's medium (MEM) supplemented with 10\% fetal bovine serum (Sigma), $100 \mathrm{IU} / \mathrm{mL}$ of penicillin and $1.25 \%$ penicillin-streptomycin, in 5\% CO2 humidified atmosphere. The cells(105) were plated on coverslips in 15,6 mm diameter 24-well plate (Corning Costar, US). Cells were observed $48 \mathrm{~h}$ until confluent. When the cells have been confluent, Hela cells were given various dose of Genistein for 90 minutes [16]. After that, the cells activated with $10 \mathrm{ng} / \mathrm{ml}$ [17] TNF$\alpha(\# 570102 ; \mathrm{R} \& \mathrm{D}$ system, Minneapolis, US) for 20 minutes [18].

\section{Immunofluoresence}

The cells were fixed in situ by paraformaldehyde $4 \%$ (Sigma-Aldrich; Buchs, Switzerland) for 15 minutes, washed three times with PBS for five minutes, and then for five minutes with PBS containing 0.1\% BSA (SigmaAldrich; Buchs, Switzerland). For the detection of HMGB1 and pp38, the cells were incubated with the HMGB1 $\operatorname{IgG}$ mouse monoclonal antibody (\#MAB1690; R\&D system, Minneapolis, US)diluted in $20 \mu \mathrm{g} / \mathrm{mL}$ in PBSBSA for $45 \mathrm{~min}$ at room temperature (RT) in a humid atmosphere. This specificity has been proved by others [19]. To remove unbound primary antibodies, cells were washed three times for 5 minutes with PBS; subsequently, the secondary antibody, FITC secondary antibody(\#F7250; Sigma-Aldrich, Buchs, Switzerland) were diluted in 1:2500 in PBS-BSA, was applied for $45 \mathrm{~min}$ at RT and unbound antibodies were removed as described above. For nuclear contrast, propidium iodide (\#81845; Sigma-Aldrich, Missouri, US) were used in 1 $\mathrm{mg} / \mathrm{mL}$ and applied for 5 minutes. In another plate, the cells were incubated with the pp38TRITC conjugated IgM mouse mono-clonal antibodyfrom (\#sc-7973 TRITC, Santa Cruz; Texas, US) diluted in 1:100 in PBS-BSA for 45 minutes. Unbound antibodies were removed, and 
cells dissolved in PBS were immediately studied with the confocal microscope.

\section{Confocal Imaging}

Confocal fluorescent image were obtained by Olympus LV1000 confocal microscope scan head with 400x objective. Sequential excitation at 488 $\mathrm{nm}$ for FITC, $568 \mathrm{~nm}$ for propidium iodide and TRITC, and was provided by argon gas lasers, respectively. Emission filter 40x/1.30 Oil UPlan FLN were used for collecting green dye and 60x/1.35 Oil Uplansapowere used for collecting red dye. For thedetection of pp38, TRITC was used in channel one. For thedetection of HMGB1, FITC was used in channel one and PI were used in channel two. After sequential excitation, green and red fluorescent of the cells was saved and analyzed by Fluoview 1.7 a version software.

\section{RESULTS AND DISCUSSION}

\section{Intensity of intracellular phospho-p38}

One of the possible causes of HMGB1 translocate from the cytosol to the intranuclearis caused by activation of p38 MAPK cascade. Activated p38 can be detected with antibodyphosphorylated p38 (pp38) which had been bound with fluorescent Rhodamine, and observed with a confocal microscope Olympus. Analysis result of thetest using One-Way ANOVA on the intensity of intracellular pp38 shows the results of homogeneity of variance with significant variance $(\mathrm{p}=0: 02)$. Results of One Way ANOVA showed average difference intensity pp38 significant $(\mathrm{p}=0.000)$ between cell culture negative control, positive control and treatment.

Post Hoc Tukey HSD study showed that p38 activity is significantly increased at dose $10 \mathrm{nM}$, $100 \mathrm{nM}$, and $50 \mu \mathrm{M}$ compared to the negative control $(\mathrm{P}<0.05)$. Meanwhile, when compared with the positive control, p38 activity was not increased significantly in all treatment doses. At dose $1 \mathrm{nM}$ and $10 \mu \mathrm{M}$ found decreased activity, though not statistically significant when compared with the positive control (Figure 1A and $1 \mathrm{~B}) \cdot \mathrm{p} 38$ activity significantly increased at a dose $10 \mathrm{nM}, 100 \mathrm{nM}$ and $50 \mu \mathrm{M}$ compared to the negative control ( $\mathrm{P}<0.05$ ). Meanwhile, when compared with the positive control, p38 activity was not significantly increased in all treatment doses. At a dose of $1 \mathrm{nM}$ and $10 \mu \mathrm{M}$ found decreased activity, though not statistically significant when compared with the positive control. Other studies have suggested that genistein inhibits the growth of HeLa cells, but increased the phosphorylation of p38 [20].

From several previous studies, opposing effect have found. Huang said that genistein 50 $\mu \mathrm{M}$ can inhibit the activation of $\mathrm{p} 38$ when given before exposure to TGF - $\beta$ [21]. Lakhsman support the statement, that genistein intake of $250 \mathrm{mg} / \mathrm{kg}$ in mice, resulted in plasma genistein concentration of $1.3 \mu \mathrm{M}$, can increase the expression of p38 but lowered it activation [22]. Both studies was conducted on cancer cells culture which are sensitive to estrogen receptors, namely PC3, PC3-M and prostate cancer cell cultures. It means that the effects of estrogen receptors on both study are still not taken into account. Another study mentioned that the genistein at dose $45 \mu \mathrm{M}$ can increase the activity of p38 from the 15th minute until 120th [16]. Several studies support statement that p38 can activate estrogen receptors in endometrial cells $[23,24]$.

In cell culture with strong expression of estrogen receptors, genistein tends to act as estrogen agonists at low concentrations $(<5$ $\mu \mathrm{M})$, and became estrogen antagonist at high concentrations $(>10 \mu \mathrm{M})$ [25]. At nanomolar concentrations, the effects of tyrosine kinase inhibition are difficult to achieve because it is too low [26]. Genistein itself has more potent selectivity toward estrogen receptor- $\beta$ than estrogen receptor- $\alpha$ [26, 27]. While in cervix cancer cells, estrogen receptor type that more dominant is estrogen receptor- $\alpha$. Decreased levels of estrogen receptor- $\alpha$ in cervical cancer cells can increase malignancy of cancer cells [28, 29, 30]. Thus, it can be presumed that there are other pathways exist in addition to the estrogen receptor- $\alpha$ and $-\beta$ that can increase the activation of p38 in our study.

Xie et al. 2013 using the genistein as an apoptosis inducer agent at a dose $15 \mathrm{mg} / \mathrm{mL}$ [31]. This made clear by other studies stating that p38 is one of the apoptosis cell intermediate [32, 33]. It explains increasing in the intensity of p38 at dose $50 \mu \mathrm{M}$, where this dose as indicated on Szliszka, et al., 2008 is apoptotic dose of genistein [34]. The results of the studies 
mentioned above, it can be concluded that genistein has different effects on different cell cultures, with different doses. The phenomenon can be affected by the estrogenic effects of genistein; receptor tendencies or genistein doses that given. Thus, it may explain the results of our

study, which low doses exposure of genistein (1$100 \mathrm{nM}$ ) increases the effect of p38 activation, whereas at higher doses $(1-10 \mu \mathrm{M}$ or more) are inhibitors for p38. At apoptotic dose, p38 increased again due to the activation of apoptotic pathways.

(-) control

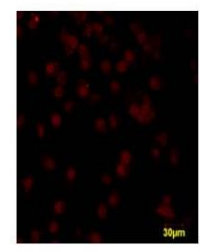

$100 \mathrm{nmol} / \mathrm{L}$

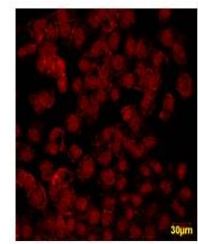

(+) control

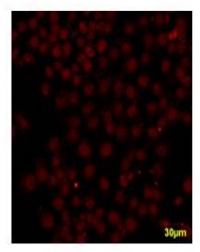

$1 \mu \mathrm{mol} / \mathrm{L}$

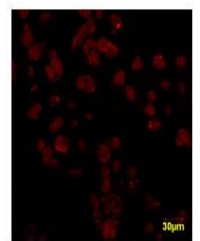

$1 \mathrm{nmol} / \mathrm{L}$

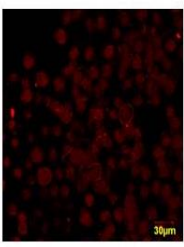

$10 \mu \mathrm{mol} / \mathrm{L}$

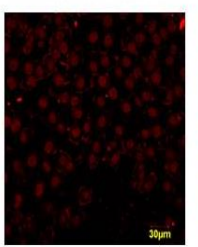

$10 \mathrm{nmol} / \mathrm{L}$

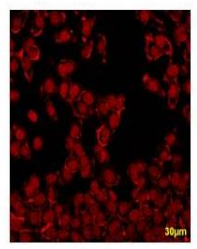

$50 \mu \mathrm{mol} / \mathrm{L}$

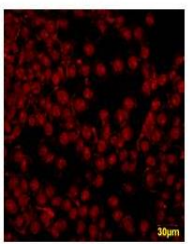

Error Bars: $+1-1 \mathrm{SD}$

A

B

Figure1. A. Comparison of the mean intensity of intracellular pp38 in cultured HeLa cells without treatment (negative control) exposed to $\mathrm{TNF}-\alpha$ treatment of $10 \mathrm{ng}$ (positive control), and with various concentrations of genistein exposure (treatment). Note : $\mathrm{K}-$ (negative control), $\mathrm{K}+$ (positive control), $1 \mathrm{~N}$ (1 nM genistein), $10 \mathrm{~N}(10 \mathrm{nM}$ genistein), $100 \mathrm{~N}$ (100 nM genistein), $1 \mathrm{M}(1 \mu \mathrm{M}$ genistein), $10 \mathrm{M}$ (10 $\mu \mathrm{M}$ genistein), dan 50M (50 $\mu \mathrm{M}$ genistein). B. P38 antibody-TRITC staining and confocal microscopy observations. HeLa cell cultures were exposed to various concentrations of genistein for 90 minutes and exposed to TNF- $\alpha 10 \mathrm{ng} / \mathrm{ml}$ for 20 minutes.

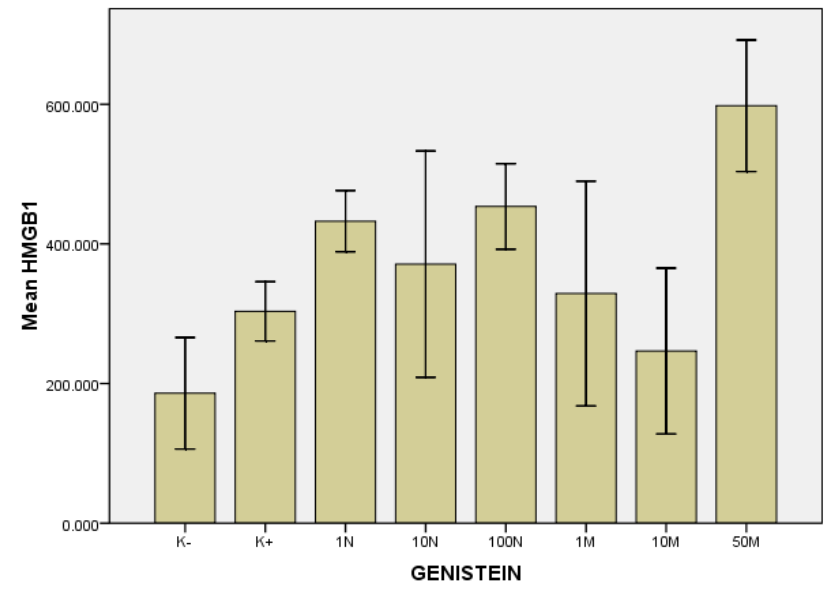

Error Bars: +/- $1 \mathrm{SD}$
$(-)$ control

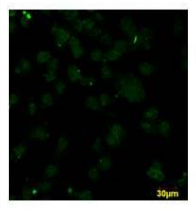

$100 \mathrm{nmol} / \mathrm{L}$

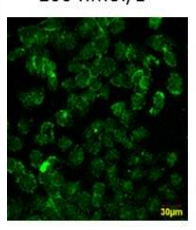

$(+)$ control

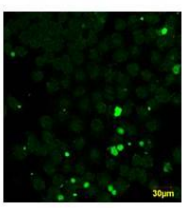

$1 \mu \mathrm{mol} / \mathrm{L}$

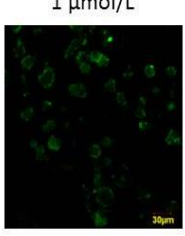

$1 \mathrm{nmol} / \mathrm{L}$

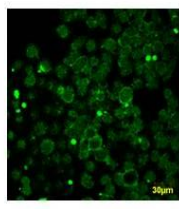

$10 \mu \mathrm{mol} / \mathrm{L}$

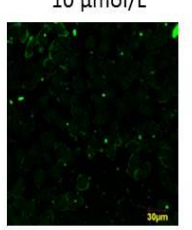

$10 \mathrm{nmol} / \mathrm{L}$

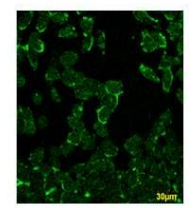

$50 \mu \mathrm{mol} / \mathrm{L}$

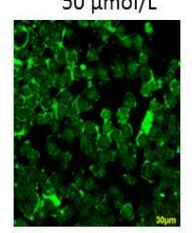

A

B

Figure 3. A. Comparison of the mean intensity of extranuclear HMGB1 in cultured HeLa cells without treatment (negative control), exposed to TNF- $\alpha$ treatment of $10 \mathrm{ng}$ (positive control), and with various concentrations of genistein exposure (treatment). Note : $\mathrm{K}-$ (negative control), $\mathrm{K}+$ (positive control), $1 \mathrm{~N}$ (1 nM genistein), $10 \mathrm{~N}(10 \mathrm{nM}$ genistein), $100 \mathrm{~N}$ (100 nM genistein), $1 \mathrm{M}(1 \mu \mathrm{M}$ genistein), $10 \mathrm{M}(10 \mu \mathrm{M}$ genistein), dan $50 \mathrm{M}(50 \mu \mathrm{M}$ genistein). B. HMGB1/FITC staining and confocal microscopy observations. HeLa cell cultures were exposed to various concentrations of genistein for 90 minutes and exposed to TNF- $\alpha 10 \mathrm{ng} / \mathrm{ml}$ for 20 minutes. 
HMGB1

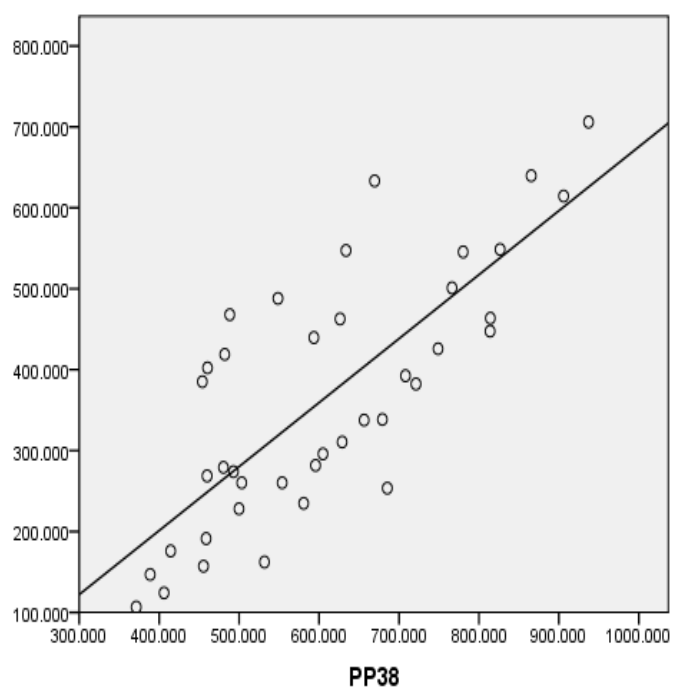

Figure 5. Pearson test results obtained that the relationship between variables is significant and substantial.

\section{Intensity of HMGB1 extranuclear}

HMGB1 which stained with primary antibodies and fluorescent FITC is coming out from intranuclear. HMGB1 fluorescence intensity was measured using a confocal microscope Olympus. Analysis of test results using One-Way ANOVA on the intensity of HMGB1 extra-nuclear shows the results of homogeneity of variance with the variance was not significant $(p=0.52)$. Results of One Way ANOVA showed average difference intensity of HMGB1 were significantly $(p=0.000)$ between cell culture negative control, positive control and treatment.

The Post Hoc Tukey HSD analysis showed that HMGB1 significantly increased the number in the cytosol at dose $1 \mathrm{nM}, 100 \mathrm{nM}$ and $50 \mu \mathrm{M}$ compared to the negative control ( $\mathrm{P}<0.05$ ). Meanwhile, when compared with the positive control, HMGB1 did not significantly increase in the cytosol in all treatment doses, except $50 \mu \mathrm{M}$ (P $<0.05)$. At dose $1 \mu \mathrm{M}$ and $10 \mu \mathrm{M}$ found decreased intensity, though not statistically significant. However compared to dose $100 \mathrm{nM}$, both dose can significantly reduce the intensity of HMGB1 in the cytosol ( $\mathrm{P}<0.05)$ (Figure 3A and 3B).

The Post Hoc Tukey HSD analysis showed that HMGB1 significantly increased the amount in the cytosol in a dose of $1 \mathrm{nM}, 100 \mathrm{nM}$ and $50 \mu \mathrm{M}$ when compared to the negative control ( $\mathrm{P}<0.05)$. Meanwhile, when compared to the positive control, HMGB1 did not increase the amount in the cytosol significantly in all treatment doses, except $50 \mu \mathrm{M}(\mathrm{P}<0.05)$. At dose $1 \mu \mathrm{M}$ and $10 \mu \mathrm{M}$ found decreased activity, though not significant statistically. However toward dose $100 \mathrm{nM}$, both treatments can significantly reduce the intensity of HMGB1 in the cytosol ( $\mathrm{p}<0.05)$. That is, in general, increasing doses of genistein also increase the amount of HMGB1 that translocated into the cytosol.

Induction of TNF- $\alpha$ can activate $\mathrm{p} 38$ pathway $[14,35]$, which finally activates MSK1 [36]. MSK1 activation would lead to activation of CREB (cAMP Response Element Binding Protein) [37]. This is confirmed by research Gustin (2004) [38], in which TNF- $\alpha$ can activate CREB through $\mathrm{p} 38$ MSK1 pathway via TNFR-1 receptor [38]. Activation of phosphorylated CREB binds to CREB-binding protein (CBP). After CBP activated, it will bind to p300 both with Histone Acetyltransferase activity [39]. Substrates of $\mathrm{CBP} / \mathrm{p} 300$ is not only histones, but also nonhistone proteins other [40], including HMGB1 [8]. Acetylated HMGB1 will be separated from DNA binding [8] because its domain of DNA on HMGB1 Nuclear Localization Sequence (NLS) experienced acetylation [39]. In addition, acetylated HMGB1 also will undergo translocation through CRM1 or exportin [41] and can not survive much longer in the nucleus [8]. This is consistent with the findings in our study where HMGB1 translocation to nucleus increased along with p38 activation. In conclusion, increasing doses of genistein increase intranuclear p38 activation and HMGB1 extra-nuclear translocation. Moreover, there were a strong linkage between p38 activation and HMGB1 translocation in this study.

Pearson test results obtained that the relationship between variables is significant, with $\mathrm{p}$ $=0.000$, which means a significant relationship between the increase in the intensity of pp38 with an increase in the intensity of HMGB1. R $=0773$ show an association with high strength. Positive value $(+)$ means that between pp38 and HMGB1 has a unidirectional relationship, the higher the intensity of $\mathrm{pp} 38$, the higher the intensity of HMGB1 (Figure 5).

\section{CONCLUSIONS}

From the experiment, it can be concluded that exposure various doses of genistein increase intranuclear p38 activation and HMGB1 
extranuclear translocations in a biphasic pattern. Genistein effects increase p38 phosphorylation and HMGB1 translocation in nanomolar doses, but decreased in micromolar doses. But overall, genistein increase p38 activation and HMGB1 acetylation. So there were a probable linkage between p38 activation and HMGB1 translocation in this study.

\section{ACKNOWLEDGMENT}

Authors are grateful to Mrs. Bunga from Biomedic Laboratory, Brawijaya University and Ms. Choirunil from Life Science Central Laboratory, Brawijaya University for their technical support. Also, the authors would like to extend their thanks to the Islamic University of Malang, Indonesia for their financial support.

\section{REFERENCES}

1. Shanta V, et al. (2000) Epidemiology of cancer of the cervix: global and national perspective. $J$ Indian Med Assoc. 98(2):49-52.

2. Greer BE, et al. (2010) Cervical Cancer : Clinical Practice Guidelines in Oncology. I Natl Compr Canc Netw. 8:1388-1416.

3. Rakoff-Nahoum S (2006) Cancer Mechanisms : Why Cancer and Inflammation?. Yale Journal of Biology and Medicine; 79: 123-130.

4. Wu Y and Zhou BP (2009) Inflammation: a driving force speeds cancer metastasis. Cell Cycle. 8(20): 3267-3273.

5. Lu H, Ouyang W and Huang Huang C (2006) Inflammation, a Key Event in Cancer Development. Mol Cancer Res. 4(4):221 - 33.

6. Harris HE and Andersson U (2004) Mini-review: The nuclear protein HMGB1 as a proinflammatory Mediator. Eur. J. Immunol. 34: 1503-1512.

7. Palumbo R, et al. (2004) Extracellular HMGB1, a signal of tissue damage, induces mesoangioblast migration and proliferation. The Journal of Cell Biology. 164(3): 441-449.

8. Bonaldi T, et al. (2003) Monocytic Cell Hyperacetylate Chromatin protein HMGB1 to Redirect It Toward Secretion. EMBO J. 22: 5551 5560 .

9. Gardella S, et al. (2002) The nuclear protein HMGB1 is secreted by monocytes via a nonclassical, vesicle-mediated secretory pathway. EMBO Rep. 3: 995-1001.

10. Scaffidi P, Misteli T and Bianchi ME (2002) Release of chromatin protein HMGB1 by necrotic cells triggers inflammation. Nature. 418(6894): 191-5.

11. Volp K, et al. (2006) Increased expression of high mobility group box 1 (HMGB1) is associated with an elevated level of the antiapoptotic c-IAP2 protein in human colon carcinomas. Gut. 55: 234242.

12. Landecker H (1996) Seeking Cellvation : Hela Cells and Immortality. s.l. : Program in Science, Technology and Society: Massachussets Institute of Technology.

13. Cargnello M and Roux P.P (2011) Activation and Function of the MAPKs and Their Substrates, the MAPK-Activated Protein Kinases. Microbiol. Mol. Biol. Rev. 75(1): 50-83.

14. Li Y W, et al. (2005) Inactivation of Nuclear Factor $x \mathrm{~B}$ by Soy Isoflavone Genistein Contributes to Increased Apoptosis Induced by Chemotherapeutic Agents in Human Cancer Cells. Cancer Res. (65): 6934-6942.

15. Wang D, et al. (2012) Tumor necrosis factor- $\alpha$ induced phosphorylation of RelA/p65 on Ser529 is controlled by casein kinase II. J. Biol. Chem. 275: 32592.

16. Frey RS and Singletary KW (2003) Genistein Activates p38 Mitogen-Activated Protein Kinase, Inactivates ERK1/ERK2 and Decreases Cdc25C Expression in Immortalized Human Mammary Epithelial Cells. J. Nutr. 133: 226-231.

17. Turner DA, et al. (2010) Physiological levels of TNF stimulation induce stochastic dynamics of NF- B responses in single living cells. Journal of Cell Science. 123(16): 2834-43.

18. Prickett TD and Brautigan DL (2007) Cytokine Activation of p38 Mitogen-Activated Protein Kinase and Apoptosis Is Opposed by alpha-4 Targeting of Protein Phosphatase 2A for SiteSpecific Dephosphorylation of MEK3. Molecular and Cellular Biology. 27(12): 4217-27.

19. Lotze MT and Tracey KJ (2005) High-mobility group box 1 protein (HMGB1): nuclear weapon in the immune arsenal. Nat. Rev. Immunol. (5): 331.

20. Kim SH, et al. (2009) Genistein inhibits cell growth by modulating various mitogen-activated protein kinases and AKT in cervical cancer cells. Ann N Y Acad Sci. 1171: 495-500.

21. Huang X, et al. (2005) Genistein Inhibits p38 Map Kinase Activation, Matrix Metalloproteinase Type 2, and Cell Invasion in Human Prostate Epithelial Cells. Cancer Res. 65: 3470-3478.

22. Lakshman M, et al. (2008) Dietary Genistein Inhibits Metastasis of Human Prostate Cancer in Mice. Cancer Res. 68: 2024-2032.

23. Seval Y, et al. (2006) Estrogen-mediated regulation of p38 mitogen-activated protein kinase in 
human endometrium. I Clin Endocrinol Metab. 91(6): 2349-57.

24. Yu HP, et al. (2011) Role of estrogen receptordependent upregulation of P38 MAPK/heme oxygenase 1 in resveratrol-mediated attenuation of intestinal injury after trauma-hemorrhage. Shock. 35(5): 517-23.

25. Wang TTY, Sathyamoorthy $\mathrm{N}$ and Phang JM (1996) Molecular effects of genistein on estrogen receptor mediated pathways. Carcinogenesis. 17 (2): 271-275.

26. McCarty MF (2006) Isoflavones made simple Genistein's agonist activity for the beta-type estrogen receptor mediates their health benefits. Medical Hypotheses. 66(6): 1093-1114.

27. Manas ES, et al. (2004) Understanding the selectivity of genistein for human estrogen receptor-beta using X-ray crystallography and computational methods. Structure. 12(12): 2197207.

28. Brake $\mathrm{T}$ and Lambert PF (2005) Estrogen contributes to the onset, persistence, and malignant progression of cervical cancer in a human papillomavirus-transgenic mouse model. PNAS. 102(7): 2490-95.

29. Zhai Y, et al. (2010) Loss of Estrogen Receptor 1 Enhances Cervical Cancer Invasion. Am J Pathol. 177(2): 884-895.

30. Chung SH, et al. (2013) Requirement for stromal estrogen receptor alpha in cervical neoplasia. Horm Cancer. 4(1): 50-9.

31. Xie X, et al. (2013) Genistein promotes cell death of ethanol-stressed HeLa cells through the continuation of apoptosis or secondary necrosis. Cancer Cell International. 13(63): 1-15.

32. Grethe S, et al. (2004) p38 MAPK mediates TNFinduced apoptosis in endothelial cells via phosphorylation and downregulation of $\mathrm{Bcl}-\mathrm{x}(\mathrm{L})$. Exp Cell Res. 15; 298(2): 632-42.

33. Dhandayuthapani S, et al. (2013) Induction of apoptosis in HeLa cells via caspase activation by resveratrol and genistein. J Med Food. 16(2): 13946.

34. Szliszka E, et al. (2008) Dietary Flavonoids Sensitize Hela Cells to Tumor Necrosis FactorRelated Apoptosis Inducing Ligand (TRAIL). Int J Mol Sci. 9(1): 56-64.

35. Zhou FH, et al. (2006) TNF-alpha mediates p38 MAP kinase activation and negatively regulates bone formation at the injured growth plate in rats. J Bone Miner Res. 21(7): 1075-88.

36. McCoy CE, et al. (2005) MSK1 activity is controlled by multiple phosphorylation sites. Biochem J. 15; 387(Pt 2): 507-17.

37. Mayer TZ, et al. (2013) The p38-MSK1 signaling cascade influences cytokine production through
CREB and C/EBP factors in human neutrophils. J Immunol. 15; 191(8): 4299-307.

38. Gustin JA, et al. (2004) Tumor necrosis factor activates CRE-binding protein through a p38 MAPK/MSK1 signaling pathway in endothelial cells. Am J Physiol Cell Physiol. 286(3): C547-55.

39. Yuan LW and Gambee JE (2001) Histone acetylation by p300 is involved in CREBmediated transcription on chromatin. Biochim Biophys Acta. 1541(3): 161-9.

40. Lu Q, et al. (2003) Acetylation of cAMPresponsive element-binding protein (CREB) by CREB-binding protein enhances CREBdependent transcription. J Biol Chem. 278(18): 15727-34.

41. Nguyen KT, Holloway MP and Altura RA (2012) Review Article The CRM1 nuclear export protein in normal development and disease. Int J Biochem Mol Biol. 3(2): 137-151. 